\title{
Plasma Lipoprotein Metabolism in Transgenic Mice Overexpressing Apolipoprotein E Accelerated Clearance of Lipoproteins Containing Apolipoprotein B
}

\author{
Hitoshi Shimano, Nobuhiro Yamada, Motoya Katsuki, “ Koji Yamamoto, Takanari Gotoda, Kenji Harada, Masako Shimada, \\ and Yoshio Yazaki \\ The Third Department of Internal Medicine, Faculty of Medicine, University of Tokyo, Bunkyo-ku, Tokyo, Japan, 113; \\ and *Japan and Central Institute for Experimental Animals, Miyamae, Kawasaki, Japan, 213
}

\begin{abstract}
We have reported that transgenic mice overexpressing rat apo E shows marked reduction of plasma cholesterol and triglyceride levels due to the disappearance of VLDL and LDL. In this study, we investigated the metabolism of plasma lipoproteins in transgenic mice. After intravenous injection, the rates of clearance of ${ }^{125} \mathrm{I}-\mathrm{VLDL}$ and ${ }^{125} \mathrm{I}-\mathrm{LDL}$ were 3.0- and 2.4-fold greater in transgenic mice than in controls, respectively. Furthermore, clearance of chylomicron remnants estimated by oral retinyl palmitate-loading test was markedly enhanced in transgenic mice. The hepatic expression of LDL receptors by immunoblot analysis was similar in both groups. These data suggest that elimination of lipoproteins containing apo $B$ was due to enhanced clearance of these lipoproteins enriched with apo $E$ through hepatic LDL receptors. When fed a high cholesterol diet, controls showed twofold elevation of plasma cholesterol levels with marked increases in VLDL and LDL cholesterol on gel filtration chromatography. In contrast, cholesterol-fed transgenic mice showed resistance against these increases. High cholesterol feeding decreased the activity of hepatic LDL receptors and had no effect on enhancement of chylomicron remnant clearance in transgenic mice. Thus, overexpression of apo $\mathbf{E}$ facilitates metabolism of lipoproteins containing apo B presumably primarily via the LDL receptor pathway and possibly through an interaction with the chylomicron remnant receptor. (J. Clin. Invest. 1992.90:2084-2091.) Key words: cholesterol • very low density lipoprotein • low density lipoprotein • chylomicron remnants $\bullet$ low density lipoprotein receptor
\end{abstract}

\section{Introduction}

Apo $\mathrm{E}$ is mainly produced in the liver and is a major constituent of mammalian lipoproteins. This protein, along with apo B 100, functions in the metabolism of plasma lipoproteins through its interaction with the LDL receptor mainly in the liver (for reviews see references 1,2 ). Apo $E$ is also thought to be a specific ligand for a putative hepatic chylomicron remnant receptor and to be involved in the metabolism of intestinal lipoproteins $(1,2)$. Furthermore, apo $\mathrm{E}$ is expressed in many

Address reprint requests to Dr. Nobuhiro Yamada, Third Department of Internal Medicine, Faculty of Medicine, University of Tokyo, Bunkyo-ku, Tokyo, Japan, 113.

Received for publication 19 February 1992 and in revised form 27 April 1992.

J. Clin. Invest.

(c) The American Society for Clinical Investigation, Inc.

0021-9738/92/11/2084/08 \$2.00

Volume 90, November 1992, 2084-2091 other tissues and plays a crucial role in the transport and redistribution of lipids in peripheral tissues such as brain, peripheral nerves, and the arterial wall $(1,3,4)$. Several lines of evidence suggest that lipoproteins containing several molecules of apo $\mathrm{E}$ have higher affinity for LDL receptors than those without apo E (1, 5-7). In vitro studies have demonstrated that VLDL particles enriched with apo $\mathrm{E}$ by exogenous addition or gene transfection of apo $\mathrm{E}$ are taken up efficiently by cultured cells (8-11). In vivo studies have also shown that lipoproteins with apo $\mathrm{E}$ are more rapidly removed from plasma than those without apo E (12-14). Recently, we and another group have reported that intravenous administration of apo $E$ lowered plasma cholesterol level in hypercholesterolemic rabbits due to enhanced clearance of VLDL $(15,16)$. These findings suggest that apo $\mathrm{E}$ functions in determining the metabolic fate of lipoproteins containing apo B100. To further investigate the role of apo $\mathrm{E}$ in vivo, we have established lines of transgenic mice with high plasma levels of apo $\mathrm{E}$, which is overproduced in the liver under the control of the metallothionein promoter (17). Homozygotes for line 4-20, the highest liver expressor, exhibited a marked reduction in plasma cholesterol and triglyceride levels, with elimination of VLDL and a marked decrease in LDL (18). They also showed resistance against diet-induced hypercholesterolemia (18). In the present study, we investigated the mechanism by which overexpression of apo $E$ caused these dramatic decreases in plasma lipoproteins containing apo B in transgenic mice. The kinetic studies of plasma lipoproteins in these animals demonstrated that overexpression of apo E markedly enhanced plasma turnover of VLDL, LDL, and chylomicron remnants through interactions with the receptors possessing high affinity for apo $\mathrm{E}$.

\section{Methods}

Materials. $\mathrm{Na}^{125} \mathrm{I},{ }^{125} \mathrm{I}$-protein A, $\left[\alpha^{32} \mathrm{P}\right] \mathrm{dCTP}$, and $\left[\gamma^{32} \mathrm{P}\right] \mathrm{ATP}$ were purchased from New England Nuclear/Dupont (Boston, MA). BSA, TCA, PMSF, and Triton X-100 were obtained from Sigma Chemical Co. (St. Louis, MO). All reagents used were of analytical grade. BDF1 mice were from Nippon Bio-supply Center (Tokyo, Japan). cDNA probes for mouse LDL receptor related protein and rat apo $B$ were kindly donated by Dr. J. Herz and Dr. A. Matsumoto, respectively.

Animals. Transgenic mice that overexpress rat apo E under the control of the metallothionein promoter, line 4-20, were established as described previously (17). Homozygous line 4-20 aged 16-20 wk were used in this study. In some experiments, heterozygotes were also used. Sibling mice that lacked the transgene or normal mice with the same genetic background ([C57BL6 $\times$ BDA] F2 hybrids) and of the same age were used as controls. These animals were maintained on normal chow and given water supplemented with $20 \mathrm{mM} \mathrm{ZnSO}_{4}$ for $>2$ wk to induce the expression of rat apo $\mathrm{E}$ from the transgene. For cholesterol feeding, some groups of the mice were fed a diet containing $1 \%$ cholesterol and $0.5 \%$ deoxycholate for 2 wk. For determination of plasma 
cholesterol levels, blood was drawn from retroorbital plexus after a 12-h fast. In some experiments, animals were anesthetized with pentobarbital and killed for resection of the liver. After blood was drawn by cardiac puncture, small aliquots of livers were immediately used or frozen at $-80^{\circ} \mathrm{C}$ until use for preparation of plasma membrane fraction or total RNA or extraction of lipids.

Analyses. Plasma cholesterol levels were determined by a commercial kit using the cholesterol oxidase method (19). Analysis of cholesterol in plasma lipoprotein classes was conducted by gel filtration chromatography (HPLC) using TSK G3000SW (Tosoh Co., Tokyo, Japan) and Superose 6 HR (Pharmacia LKB Biotechnology, Uppsala, Sweden ) as previously described (18).

Retinyl palmitate-loading test. After a 4-h fast, the animals were orally administered $2 \mathrm{mg}$ (for mice fed a normal diet) and $0.5 \mathrm{mg}$ (for mice fed a cholesterol diet) of retinyl palmitate in an aqueous form dissolved in $18 \%$ castor oil (Chocola A; Eisai Co., Ltd., Tokyo, Japan) orally through a gastric cannula. Blood samples were drawn before and at $0.5,1,2,4$, and $8 \mathrm{~h}$ after loading. During the experiment, the animals were fasted with access to water ad lib. The animals tolerated the loading well without symptoms of malabsorption, such as diarrhea. Venous blood was drawn from the retroorbital plexus and transferred to a tube containing sodium EDTA. Samples $(\sim 50-100 \mu l)$ were immediately centrifuged and plasma was stored wrapped in foil at $-20^{\circ} \mathrm{C}$ before retinyl palmitate assay.

Retinyl palmitate assay. The pooled plasma samples were diluted to $0.2 \mathrm{ml}$ with saline and mixed with $1 \mathrm{ml}$ of water and $1 \mathrm{ml}$ of ethanol. The mixture was mixed vigorously with $5 \mathrm{ml}$ of hexane containing $0.05 \%$ BHT. The hexane phase $(4 \mathrm{ml})$ was separated by centrifugation at $1,000 \mathrm{rpm}$ for $5 \mathrm{~min}$ and evaporated to dryness under nitrogen. The residue was dissolved in $100 \mu \mathrm{l}$ of isopropanol, and an aliquot was injected into the HPLC column (Nucleosil C18; Nargel, Düren, Germany). Ethanol/water (95:5) was used as the mobile phase at a flow rate of $0.5 \mathrm{ml} / \mathrm{min}$. The column effluent was monitored fluorometrically with $E_{x}$ at $330 \mathrm{~nm}$ and $E_{m}$ at $480 \mathrm{~nm}$. The peaks of retinol and retinyl palmitate were identified by comparison to the retention times of respective purified standards. The amounts of retinol and retinyl palmitate were determined by proportional comparison of the peak heights of samples and standards.

Lipoproteins and iodination. Blood was drawn and pooled from 10 control mice and 10 heterozygous mice by cardiac puncture. Fresh plasma was separated with $1 \mathrm{mg} / \mathrm{ml}$ disodium EDTA, $0.2 \mathrm{mg} / \mathrm{ml} \mathrm{so-}$ dium azide, and $300 \mu \mathrm{g} / \mathrm{ml}$ benzamidine. To separate VLDL, intermediate density lipoprotein (IDL) ${ }^{1}, \mathrm{LDL}$, and HDL, plasma was ultracentrifuged in a rotor (model 40.3; Beckman Instruments, Fullerton, CA) at $38,000 \mathrm{rpm}$ at $12^{\circ} \mathrm{C}$ at the sequential $\mathrm{KBr}$ densities of $1.006,1.019$, 1.063 , and 1.21 for $16,18,20$, and $48 \mathrm{~h}$, respectively (20). The floated lipoproteins were dialyzed against $150 \mathrm{mM} \mathrm{NaCl}, 2 \mathrm{mM}$ sodium phosphate, $\mathrm{pH} 7.4,0.1 \mathrm{mg} / \mathrm{ml}$ EDTA, and $0.2 \mathrm{mg} / \mathrm{ml}$ sodium azide. VLDL, LDL, and HDL were iodinated with ${ }^{125} \mathrm{I}$ by the method of McFarlane (21) with slight modification. After removal of free iodine on a column of Sephadex G 50 (PD 10; Pharmacia Inc., Piscataway, $\mathrm{NJ}$ ), the iodinated lipoproteins were dialyzed against 5 liters of the same buffer with four exchanges and finally against the same buffer without EDTA and sodium azide.

Kinetic studies. Iodinated lipoproteins $(250-500 \mu \mathrm{Ci} / 100 \mu \mathrm{l}$ per animal) were injected into mice as a bolus via the tail vein. Blood was taken $1 \mathrm{~min}$ after the injection as zero time and at the specified times by puncture of the retroorbital plexus. Plasma ( $30 \mu \mathrm{l})$ was isolated from each blood sample. For the kinetic studies of VLDL and LDL, plasma was diluted to $0.5 \mathrm{ml}$ with saline containing human LDL $(0.5 \mathrm{mg}$ protein $/ \mathrm{ml}$ ) as carrier, followed by addition of $0.5 \mathrm{ml}$ isopropanol, and was kept at room temperature for $1 \mathrm{~h}$ to precipitate apo $\mathrm{B}$. The mixture was centrifuged at $13,000 \mathrm{rpm}$ for $10 \mathrm{~min}$ in a microfuge tube (22). The radioactivities in the mixture and half volume of the supernatant

1. Abbreviations used in this paper: IDL, intermediate density lipoprotein; LRP, LDL receptor-related proteins. were counted with a gamma counter. The apo B radioactivity was calculated as follows: apo B radioactivity in pellet $(\mathrm{cpm})=$ total plasma radioactivity $(\mathrm{cpm})$ - radioactivity in supernatant $(\mathrm{cpm})$. For the turnover studies of HDL, plasma was diluted to $0.5 \mathrm{ml}$ with saline containing $1 \mathrm{mg} / \mathrm{ml} \mathrm{BSA}$, followed by addition of $0.1 \mathrm{ml} \mathrm{50 \%} \mathrm{TCA.} \mathrm{After}$ centrifugation, the count of the precipitate in 10\% TCA was measured. The removal rate of each lipoprotein was calculated from the plasma disappearance curve by the method of Matthews (23).

Immunoblot analysis for hepatic $L D L$ receptor. The immunoblot was performed as previously described (24). All of the following procedures were carried out in an ice box. An aliquot of liver $(1 \mathrm{~g})$ in $40 \mathrm{ml}$ of ice-cold buffer containing the following $(\mathrm{mM}) ; 150 \mathrm{NaCl}, 10$ Tris $\mathrm{HCl}$, $1 \mathrm{CaCl}_{2}$, and $1 \mathrm{PMSF}$, pH 8.0 was minced and homogenized with Polytron at the setting of 5 for $20 \mathrm{~s}$ (Kinematica GmbH, Littau, Switzerland). From the liver homogenates, membrane pellets $(8,000$ 100,000 -g pellets) were prepared according to Kovanen's method (25). The resultant pellets were rapidly frozen at $-80^{\circ} \mathrm{C}$ before use. The membrane pellet was resuspended in lysis buffer containing $50 \mathrm{mM}$ Tris-maleate, $2 \mathrm{mM} \mathrm{CaCl}_{2}, 1 \%$ Triton X-100, and $1 \mathrm{mM} \mathrm{PMSF}, \mathrm{pH}$ 6.5. The protein content of each lysate was measured with a BCA (bicinchoninic acid) protein assay kit (Pierce Chemical Co., Rockford, IL). Each sample containing $200 \mu \mathrm{g}$ of protein was adjusted to $1 \%$ SDS, $50 \mathrm{mM}$ Tris $\mathrm{HCl}, \mathrm{pH} 6.8,10 \%$ glycerol, and $0.1 \%$ bromphenol blue, without heating or adding reducing agent. The samples were then subjected to SDS-PAGE ( $7 \%$ gel ) at $10 \mathrm{~mA}$ at $4^{\circ} \mathrm{C}$ for $12 \mathrm{~h}$ according to the method of Laemmli (26). After electrophoresis, the samples were electrophoretically transferred to nitrocellulose membranes in buffer containing $20 \mathrm{mM}$ Trisbase, $150 \mathrm{mM}$ glycine, $0.02 \%$ SDS, and $20 \%$ methanol at $200 \mathrm{~mA}$ for $16 \mathrm{~h}$. The sheets were immersed in blocking buffer containing $150 \mathrm{mM} \mathrm{NaCl}, 10 \mathrm{mM}$ Tris $\mathrm{HCl}, \mathrm{pH} \mathrm{7.4}$, and $50 \mathrm{mg} / \mathrm{ml}$ BSA for $1 \mathrm{~h}$ at room temperature and incubated with the same buffer containing anti-LDL receptor serum, for $24 \mathrm{~h}$ at $4^{\circ} \mathrm{C}$. Polyclonal antibody against rabbit LDL receptor was produced as described previously (27). The sheets were then washed twice for $15 \mathrm{~min}$ with washing buffer containing $150 \mathrm{mM} \mathrm{NaCl}, 50 \mathrm{mM}$ Tris $\mathrm{HCl}, \mathrm{pH} 7.4,0.1 \%$ SDS, $0.2 \%$ Nonidet $\mathrm{P} 40$, and $0.25 \%$ deoxycholate and incubated in the buffer containing ${ }^{125}$ I-protein A $(2,000 \mathrm{cpm} / \mathrm{ng}, 0.5 \mu \mathrm{g} / \mathrm{ml})$ for $5 \mathrm{~h}$ at room temperature. The sheets were washed again, air-dried, and autoradiographed on $\mathrm{x}$-ray film.

Preparation and analysis of total RNA. Total cellular RNA was isolated by extraction with acid guanidinium thiocyanate, phenol, and chloroform as described by Chomczynski and Sacchi (28). Then $15 \mu \mathrm{g}$ of total RNA was subjected to electrophoresis in formaldehyde-agarose $(1 \%)$ gel, and transferred to a nylon membrane. The filter was baked, prehybridized, and hybridized as described previously (24) with the respective labeled probes. The probes used were the $1.55 \mathrm{kbp}$ EcoRI fragment of rat apo B cDNA (29) and the NotI-XhoI fragment of mouse LDL receptor-related protein cDNA (30) labeled by random primer method ( 31 ) and 5 ' end-labeled synthetic oligonucleotides that were the rat apo E-specific sequence $(32,33)$ and the corresponding mouse apo E-specific sequence: CCACTGGGGTGATGATGGG.

Determination of liver content of esterified and unesterified cholesterol. Homozygous transgenic mice and control mice fed a normal diet or high cholesterol diet were anesthetized with pentobarbital and the liver was resected. A small portion $(0.2 \mathrm{~g})$ of liver tissue from each mouse was homogenized with a Polytron homogenizer in $4 \mathrm{ml}$ of chloroform/methanol $(2: 1$, vol/vol $)$. Then, $0.2 \mathrm{ml}$ of $50 \mathrm{mM} \mathrm{NaCl}$ was added to $1 \mathrm{ml}$ of the mixture, followed by centrifugation. An aliquot of the organic phase ( $10 \mu \mathrm{l}$ for determination of total cholesterol content of liver from cholesterol-fed mice, $50 \mu \mathrm{l}$ for other samples) was evaporated under nitrogen. The residual lipids were used for determination of esterified and unesterified cholesterol content using commercial kits.

\section{Results}

Expression of apo $E$ and plasma cholesterol levels. Homozygotes for transgenic line 4-20 harboring the metallothionein promoter-rat apo $\mathrm{E}$ fusion gene were maintained on water con- 


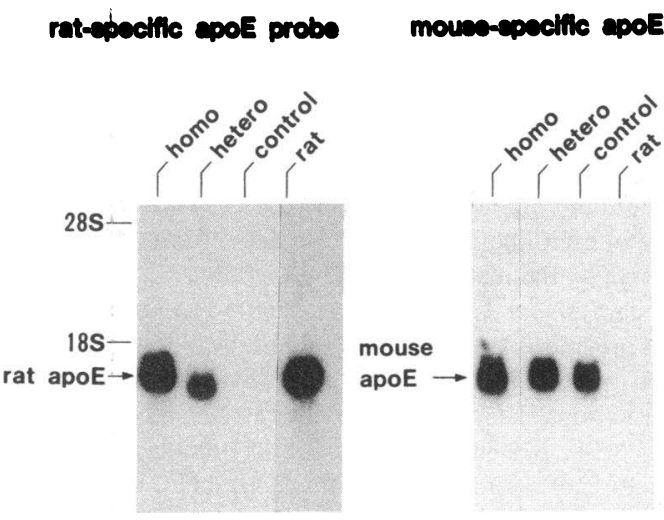

Figure 1. Northern blot analysis of livers from transgenic mice using oligonucleotide probes specific to rat apo $\mathrm{E}$ and mouse apo $\mathrm{E}$. All animals were given water containing $20 \mathrm{mM} \mathrm{ZnSO}_{4}$ to induce expression of the transgene. Hepatic total RNA (15 $\mu \mathrm{g})$ from homozygous (homo) and heterozygous (hetero) rat apo $\mathrm{E}$ transgenic mice was separated by agarose gel electrophoresis, transferred to a nylon membrane, and hybridized with differential oligosynthetic probes specific for rat apo E or mouse apo E. Hepatic RNA from Wister rat and nontransgenic mouse was also analyzed as respective controls.

taining zinc sulfate to induce the expression of the transgene. Fig. 1 shows Northern blot analyses using differential specific probes for rat and mouse apo E mRNAs. Rat apo E mRNA level in the liver of homozygotes was twice that of heterozygotes, indicating that both integrated genes were expressed in homozygotes. This mRNA level in homozygotes is almost as high as that in rats. The levels of mouse endogenous apo $\mathrm{E}$ mRNA in the transgenic lines were equivalent to that of controls, suggesting that expression of the transgene has no effect on endogenous expression of mouse apo $E$. Thus, it was confirmed that the effect of rat apo $E$ from the transgene product should be additive to that of endogenous mouse apo $E$.

Plastna cholesterol levels were compared with those of normal control mice with the same genetic background. Com- pared with controls ( $89.8 \pm 11.5 \mathrm{mg} / \mathrm{dl}, n=20)$ homozygotes showed a $60 \%$ decrease in plasma cholesterol level $(36.1 \pm 11.9$ $\mathrm{mg} / \mathrm{dl}, n=20$ ), which was greater than that previously reported in six homozygous mice $(43 \%)(18)$. Heterozygotes showed an intermediate level $(69.8 \pm 18.5 \mathrm{mg} / \mathrm{dl}, n=20)$. When control mice were fed a high cholesterol diet containing $1 \%$ cholesterol and $0.5 \%$ deoxycholate for $14 \mathrm{~d}$, plasma cholesterol levels were elevated to $191 \pm 41.4 \mathrm{mg} / \mathrm{dl}(n=20)$. In contrast, homozygous and heterozygous transgenic mice showed a level of $83.4 \pm 17.7 \mathrm{mg} / \mathrm{dl}$ and $125 \pm 37.1 \mathrm{mg} / \mathrm{dl}$, respectively $(n$ $=20$ ).

These data are consistent with previously reported results in a small number of animals (18). Fig. 2 shows the profile of plasma lipoprotein cholesterol by gel filtration chromatography in high cholesterol-fed mice. Controls fed a normal diet showed three peaks of VLDL, LDL, and HDL. In the previous study, disappearance of VLDL and a marked (80\%) decrease in LDL were observed in homozygous transgenic mice (18). Compared with controls on a normal diet, cholesterol-fed controls showed a large and steep peak of VLDL and a broad peak composed of LDL and probably IDL, indicating that the rise in plasma cholesterol levels was caused by increases in cholesterol contents of lipoproteins containing apo B. In contrast, the increases in VLDL and LDL cholesterols in homozygotes were much smaller and were similar to those of controls fed a normal diet. Heterozygotes showed intermediate levels of both classes. There was no difference in HDL cholesterol levels among the three groups, although these values were slightly lower than that of controls fed a normal diet.

Plasma turnover of lipoproteins. To study the clearances of plasma lipoproteins in the transgenic lines, kinetic studies of each lipoprotein class were performed (Fig. 3). Because homozygotes have an undetectable level of plasma VLDL and a very low level of LDL, it was very difficult to separate sufficient amounts of VLDL and LDL from homozygotes to conduct the turnover studies. We therefore obtained each class of lipoprotein from the plasma of 10 heterozygotes. Respective lipoproteins were iodinated and injected into homozygotes. Iodinated

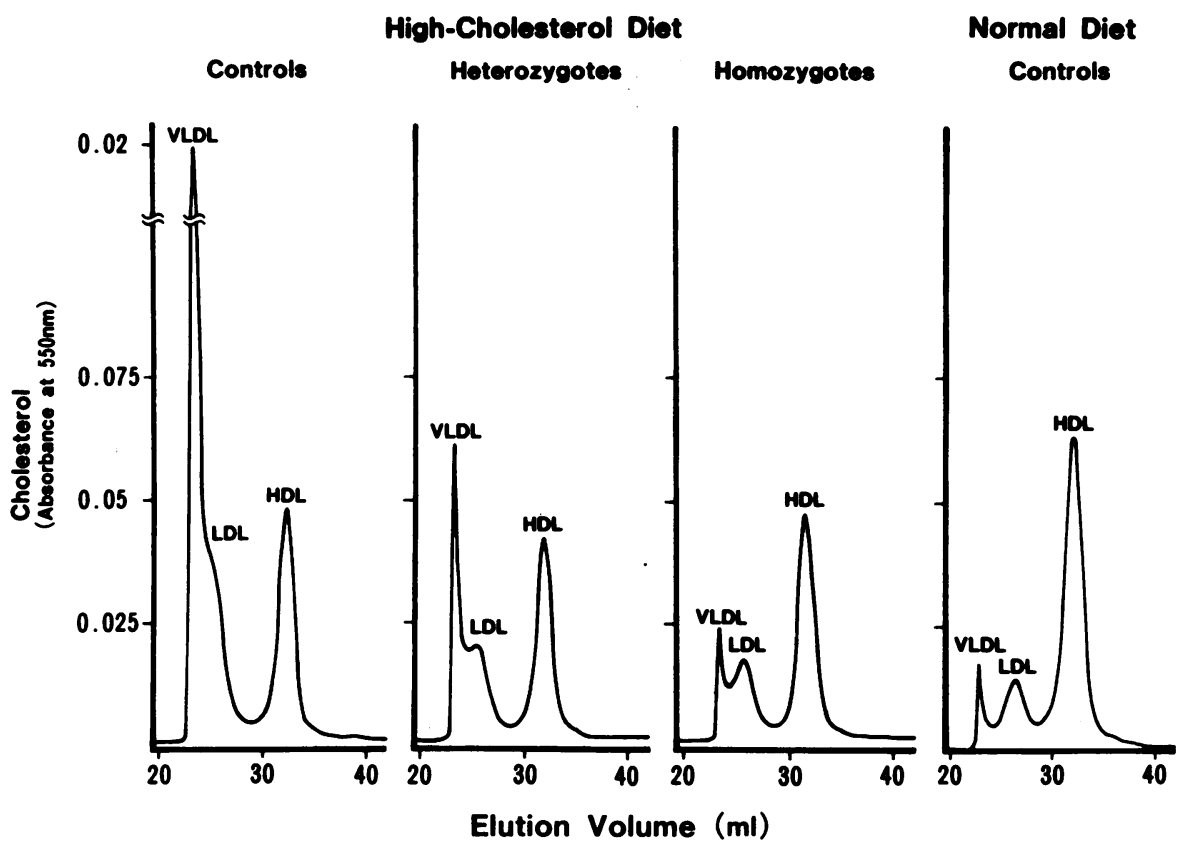

Figure 2. Profile of plasma lipoprotein cholesterol by gel filtration chromatography in cholesterol-fed transgenic mice. Homozygous and heterozygous transgenic mice and non-transgenic control mice were maintained on a high cholesterol diet and water containing $20 \mathrm{mM} \mathrm{ZnSO}_{4}$ for $14 \mathrm{~d}$. A $10-\mu 1$ sample of pooled fasting plasma from each group was applied to an HPLC system composed of TSK G3000SW and Superose 6 HR as described in Methods. Plasma cholesterol level of each group is shown in the text. The peak positions of VLDL, LDL, and HDL are indicated. IDL cholesterol may be between VLDL and LDL peaks in cholesterol-fed mice. The profile of plasma from control mice on a normal diet is also shown for comparison. 


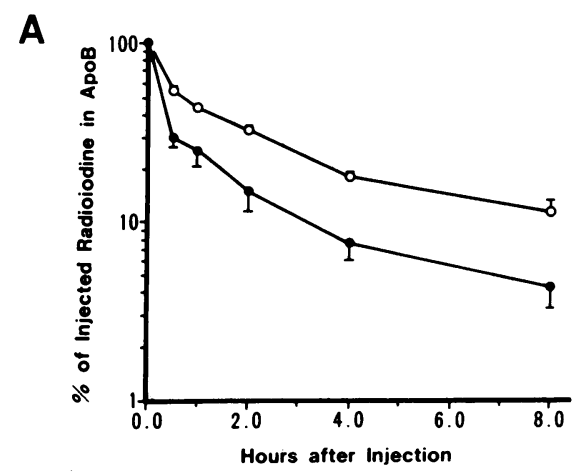

B

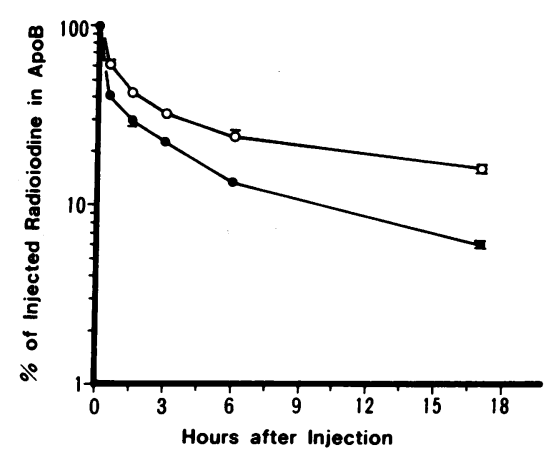

C

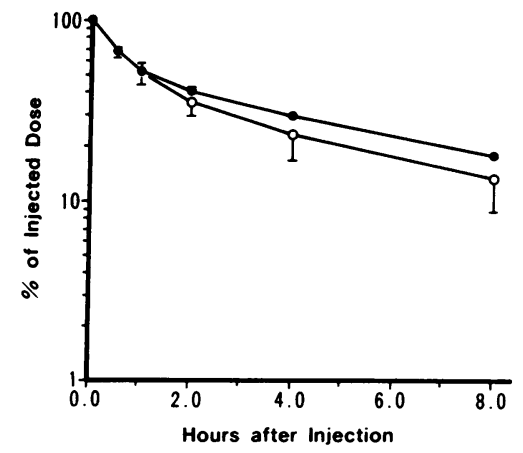

Figure 3. Plasma turnover of lipoproteins in transgenic mice. $(A)$ VLDL, $(B) \mathrm{LDL},(C) \mathrm{HDL}$. Each lipoprotein class was prepared from plasma samples from 10 zinc-induced heterozygous transgenic mice and nontransgenic controls. Each lipoprotein fraction from heterozygotes and controls was labeled with ${ }^{125} \mathrm{I}$ and injected intravenously via the tail vein into other sets $(n=3)$ of homozygotes and controls, respectively $\left({ }^{125} \mathrm{I}-\mathrm{VLDL},{ }^{125} \mathrm{I}-\mathrm{LDL}, 250 \mu \mathrm{Ci} /\right.$ animal; ${ }^{125} \mathrm{I}-\mathrm{HDL}, 500$ $\mu \mathrm{Ci}$ /animal). At specified times, plasma samples were taken. For the kinetic studies of ${ }^{125}$ I-VLDL and ${ }^{125}$ I-LDL, the percentage of injected radioiodine in apo B was measured. For the kinetic study of ${ }^{125} \mathrm{I}-\mathrm{HDL}$, the percentage of injected TCA-precipitable radioiodine was measured. The values are expressed as mean $\pm \mathrm{SE} \%(n=3$, bars; where not shown, SE values fall within data points. closed circle, transgenic mice; open circle, controls). The first plasma sample was obtained $1 \mathrm{~min}$ after injection and was used to set the value at zero time. The recovery of radioiodine in apo $B$ at zero time calculated from body weight was $>90 \%$ of total injected radioiodine in apo B in each animal. The percent apo B in counts of injected ${ }^{125} \mathrm{I}-\mathrm{VLDL}$ from transgenic and control mice was 50 and $55 \%$, respectively. The percent apo $B$ of injected ${ }^{125}$ I-LDL was $60 \%$ in both groups.

lipoproteins prepared from 10 normal control mice were injected into another set of control animals. Fig. $3 A$ shows plasma disappearances of ${ }^{125} \mathrm{I}-\mathrm{VLDL}$. The clearance of VLDL was markedly accelerated in transgenic mice compared with controls. The removal rates in transgenic and control mice were $23.1 \pm 1.4$ and $7.8 \pm 0.5$ pools $/ \mathrm{d}(n=3)$, respectively. As shown in Fig. $3 B,{ }^{125} \mathrm{I}-\mathrm{LDL}$ was also removed 2.4 -fold faster in the transgenic mice than in controls (removal rates: $8.3 \pm 1.8 \mathrm{vs}$. $3.4 \pm 0.1$ pools $/ \mathrm{d}, n=3$ ). In contrast, the clearance of ${ }^{125} \mathrm{I}-\mathrm{HDL}$ was not significantly different between the two groups, especially in the time interval shortly after injection (Fig. $3 C$ ).

Retinyl palmitate-loading test. The retinyl palmitate tolerance test was conducted to investigate plasma turnover of chylomicron remnants in homozygous and heterozygous transgenic lines and controls (Fig. $4 A$ ). No retinyl palmitate was
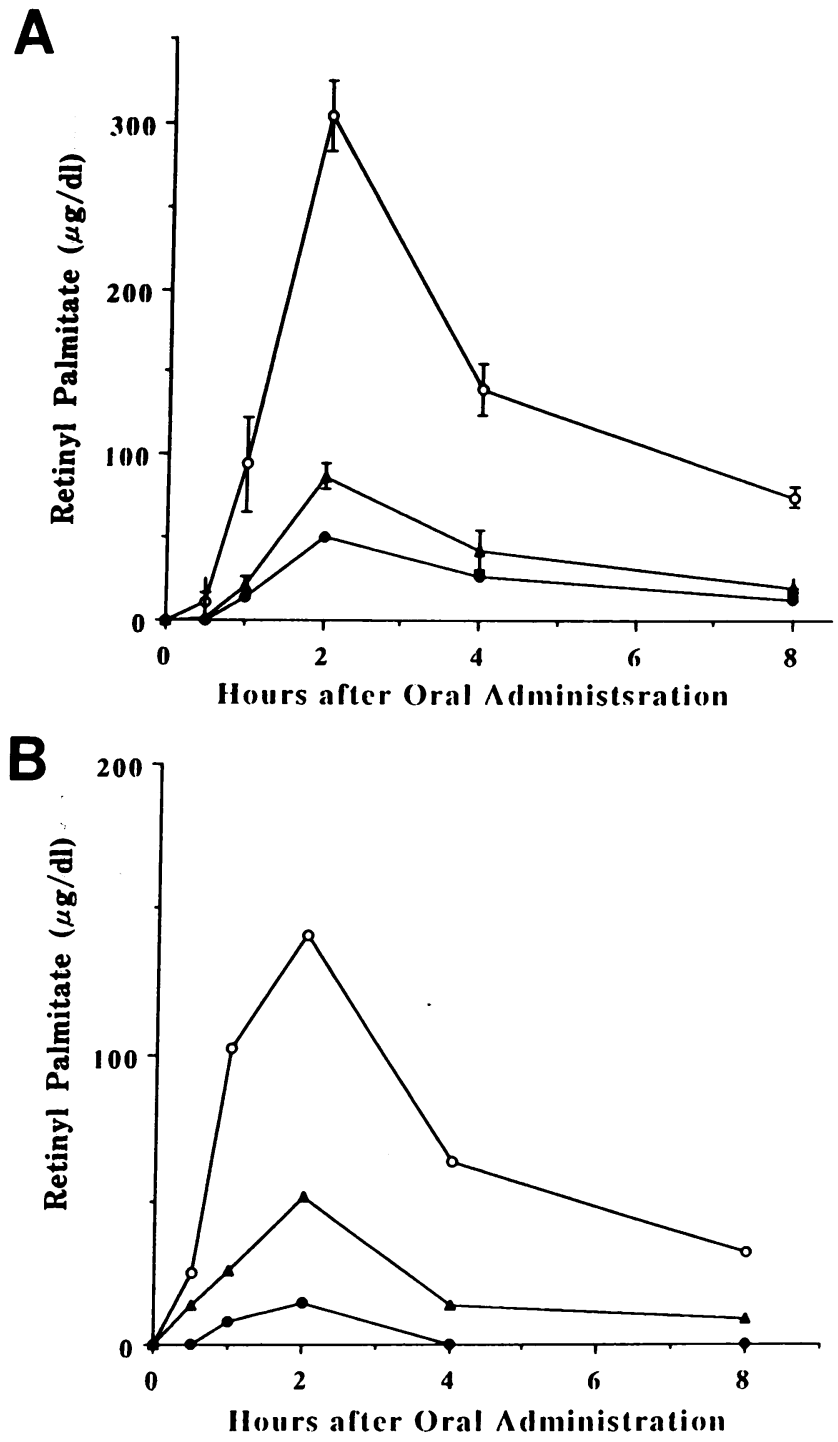

Figure 4. Plasma retinyl palmitate levels in transgenic mice on a $(A)$ normal diet and $(B)$ high cholesterol diet after oral administration. Aqueous retinyl palmitate ( $2 \mathrm{mg}$ for animals on a normal diet, 0.5 $\mathrm{mg}$ for high cholesterol-fed animals) was orally administered to homozygous and heterozygous transgenic mice and controls $(n=3)$. At specified times, blood was taken. Plasma samples were separated, pooled, and the levels of retinyl palmitate and retinol $(\mu \mathrm{g} / \mathrm{dl})$ were determined by HPLC as described in Methods (closed circle, homozygotes; closed triangle, heterozygotes; open circle, controls). For the animals on a normal diet, the values are mean $\pm \mathrm{SE}(\mu \mathrm{g} / \mathrm{dl})$ from three independent experiments (bars; where not shown, $S E$ values fall within data points.). 


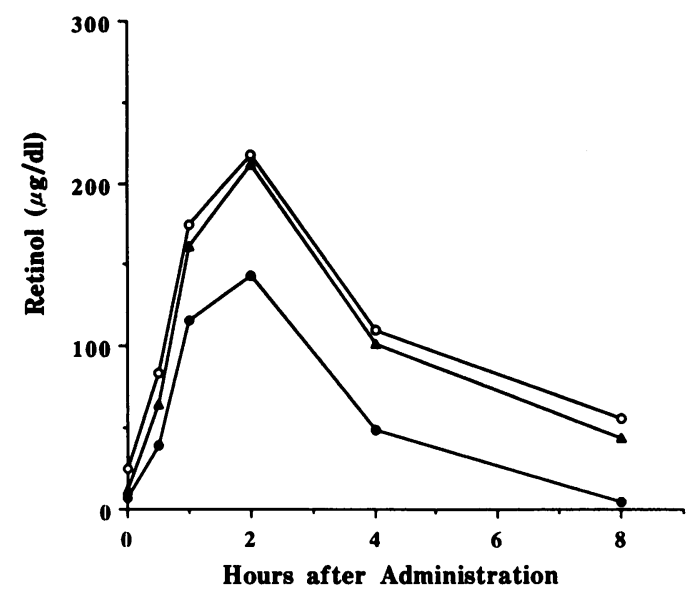

Figure 5. Plasma retinol levels in transgenic mice after oral administration. Free retinol levels $(\mu \mathrm{g} / \mathrm{dl})$ were measured in pooled plasma samples from animals on a normal diet after oral retinyl palmitateloading test as described in Fig. 4. (closed circle, homozygotes; closed triangle, heterozygotes; open circle, controls)

detected before the oral challenge in any animal. A peak of plasma retinyl palmitate level was observed at $2 \mathrm{~h}$ after loading in controls. At each time point, the mean plasma retinyl palmitate level was highest in controls, intermediate in heterozygotes, and lowest in homozygotes. For both peak height and area under the curve, the values in homozygotes were $<20 \%$ of those in controls. To evaluate intestinal absorption and hepatic uptake of the administered retinyl palmitate, the changes in plasma free retinol levels were also compared between groups (Fig. 5). Unlike retinyl palmitate, considerable levels of plasma retinol were detectable before loading in controls, heterozygotes, and homozygotes in descending order of magnitude. Each group showed a sluggish peak at $2 \mathrm{~h}$ after oral administration of retinyl palmitate. The peak area for homozygotes was $80 \%$ of that of controls and heterozygotes had a similar area to controls. The clearance of chylomicron remnants in each group after high cholesterol feeding was also assessed by retinyl palmitate-loading test (Fig. $4 \mathrm{~B}$ ). Cholesterol-fed homozygotes showed higher clearance than cholesterol-fed controls to the same degree as observed on a normal diet. In one

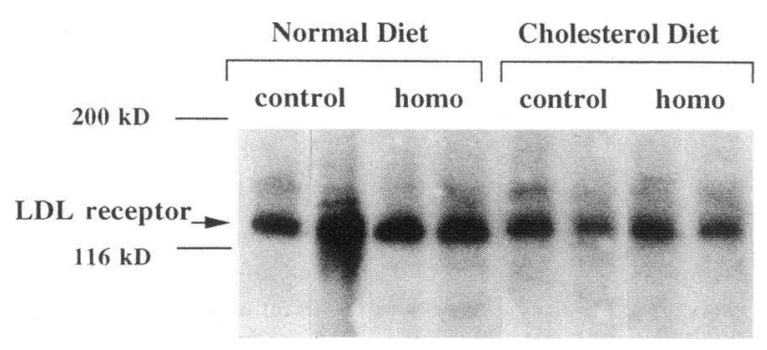

Figure 6. Immunoblot analysis of hepatic LDL receptor proteins in transgenic mice fed a normal and a high cholesterol diet. Plasma membranes ( $200 \mu \mathrm{g}$ protein) prepared from the livers of each group $(n=2)$ were electrophoresed on $7 \%$ SDS polyacrylamide gel and electrophoretically transferred to a nitrocellulose membrane. The membrane was incubated with anti-rabbit LDL receptor antibody, sequentially with ${ }^{125} \mathrm{I}$-protein $\mathrm{A}$, and autoradiographed. Molecular mass standards are indicated.

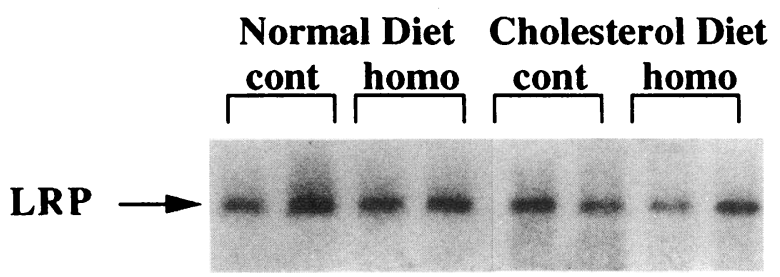

Figure 7. Northern blot analysis of hepatic LRP mRNA from transgenic mice on a normal and a high cholesterol diet. Total RNA ( 15 $\mu \mathrm{g})$ prepared from the livers of each group $(n=2)$ was subjected to Northern blot analysis using cDNA probe for LRP.

cholesterol-fed homozygous mouse, no plasma retinyl palmitate was detected at any time point with this method.

Hepatic LDL receptors by immunoblot and $m R N A$ level of $L R P$. The enhanced clearance of lipoproteins containing apo $B$ may be attributable to increased LDL receptor activity in the transgenic lines. To test this possibility, hepatic LDL receptors were compared on immunoblot analysis. As shown in Fig. 6, hepatic LDL receptors of homozygotes and controls had equivalent protein level. After cholesterol feeding, expression of the receptors was decreased in both groups and no significant difference was found between both groups. This result suggests that LDL receptor activity is not involved in the lower plasma levels of lipoproteins containing apo B in transgenic mice compared with controls. mRNA levels of LDL receptor-related proteins (LRP) were also compared (Fig. 7). There were no significant differences between the two groups and no consistent changes when a high cholesterol diet was fed.

Esterified and unesterified cholesterol contents in the livers. As shown in Table I, the major proportion of liver cholesterol was unesterified in mice fed on a normal diet. There was no significant difference in esterified and free cholesterol content between control and transgenic mice. High cholesterol feeding caused a marked increase in liver content of esterified cholesterol in both groups with a similar degree of magnitude, suggesting that dietary cholesterol was absorbed into the liver in both groups.

Expression of apo $B$. Blot hybridization analysis of liver RNA with apo B cDNA probe is shown in Fig. 8. No significant difference was found in apo B mRNA levels between homozygotes and controls. After high cholesterol feeding, a slight (densitometrically 1.4-fold) increase in apo B expression was observed in both groups. To analyze the relative amounts of two apo B molecules, apo B100 and apo B48, aliquots of VLDL

Table I. Cholesterol Contents in Livers

\begin{tabular}{lccllc}
\hline & \multicolumn{2}{c}{ Normal diet } & & \multicolumn{2}{c}{ High cholesterol diet } \\
\cline { 2 - 3 } \cline { 6 - 6 } & Control & Transgenic & & Control & Transgenic \\
\hline Unesterified & $2.4 \pm 0.10$ & $2.3 \pm 0.09$ & & $2.4 \pm 1.0$ & $2.6 \pm 0.15$ \\
Esterified & $1.2 \pm 0.50$ & $1.6 \pm 0.51$ & & $9.5 \pm 0.47$ & $11.0 \pm 1.3$
\end{tabular}

Livers were resected from homozygous transgenic mice and nontransgenic controls on a normal diet and on a high cholesterol diet. After lipid extraction, esterified and unesterified cholesterol contents were measured. Values were expressed as mean $\pm \mathrm{SE} \mathrm{mg} / \mathrm{g}$ tissue $(n=3)$. 
and LDL obtained for turnover studies were subjected to electrophoresis on SDS polyacrylamide gel (Fig. 9). VLDL separated from controls contained a higher level of apo B48 (with an apparent molecular mass of $260 \mathrm{kD}$ ) than apo B100 (550 $\mathrm{kD})$. VLDL from heterozygotes possessed almost equal amounts of apo B48 and apo B100. LDL from both groups contained a greater amount of apo B100 than apo B48. The ratios of apo B48 to apo B100 in control VLDL, transgenic VLDL, control LDL, and transgenic LDL by a densitometric scan were $2.0,1.0,0.5$, and 0.3 , respectively.

\section{Discussion}

The present study clarified the mechanism of the marked reduction of lipoproteins containing apo B in transgenic mice overexpressing apo E. Kinetic studies demonstrated that VLDL is cleared markedly faster in homozygotes than in controls. In particular, in the initial phase (the first hour) the acceleration was remarkable, contributing to an efficient plasma removal of VLDL in transgenic mice. In our previous study, we observed that rat apo $\mathrm{E}$ molecules from the transgene were distributed among all lipoprotein classes (18). Therefore, VLDL particles in transgenic lines were enriched with rat apo $\mathrm{E}$ and acquired higher affinity for the LDL receptor, resulting in enhanced uptake presumably primarily by the liver. The clearance of VLDL in homozygotes was so rapid that these particles were eliminated from the circulation. This is consistent with the in vitro data that the cultured cells secreting rat apo $E$ take up VLDL in the medium more efficiently than control cells in the study of $\mathrm{CHO}$ cells transfected with a plasmid containing the fusion gene used in this study (11). Interestingly, when ${ }^{125}$ I-labeled human VLDL was injected, the turnover was very similar among controls and heterozygous and homozygous transgenic mice (data not shown). The data suggest that the transfer of apo $\mathrm{E}$ between lipoproteins in plasma is not so rapid and that enrichment of VLDL with apo $E$ in transgenic mice might occur rather locally in the liver. SDS-PAGE showed that mouse VLDL contains both apo B100 and apo B48, and that the ratio of apo B48 to apo B100 in VLDL in heterozygotes is lower than in controls, suggesting more rapid clearance of VLDL containing apo B48 than VLDL containing apo B100 when enriched with apo E. Furthermore, the turnover of LDL was also faster in transgenic mice than in controls. Unlike human LDL, a considerable proportion of plasma apo $\mathrm{E}$ was distributed on LDL in normal and transgenic mice (control: $17 \%$, heterozygotes: $19 \%$, and homozygotes: $9 \%$ ) (18). At a rough estimate from apparent molecular masses of apo $\mathrm{E}$ and apo B,

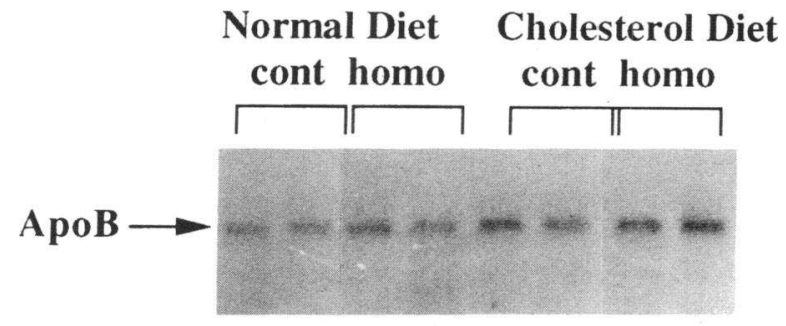

Figure 8. Northern blot analysis of hepatic apo B mRNA from transgenic mice on a normal and a high cholesterol diet. Total RNA $(15 \mu \mathrm{g})$ prepared from the livers of each group $(n=2)$ was subjected to Northern blot analysis using cDNA probe for apo $B$.

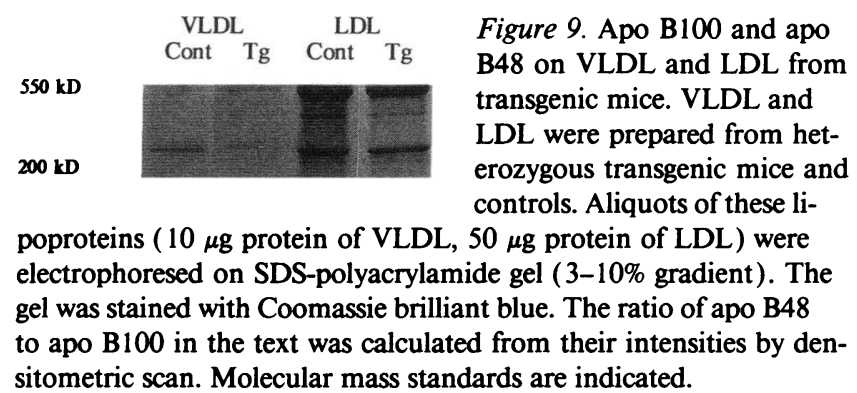

numbers of apo $\mathrm{E}$ molecules on both VLDL and LDL particles were increased approximately fourfold in heterozygous transgenic mice compared with respective controls. These additional apo E molecules on LDL particles may increase their affinity for the LDL receptor, as observed with VLDL. Thus, the decrease in LDL cholesterol in homozygotes is attributed not only to decreased lipolytic conversion from VLDL that has disappeared from plasma, but also to enhanced clearance of LDL enriched with apo E. Since transgenic mice have the same LDL receptor activity as controls (Fig. 6), enhanced clearance of VLDL and LDL in transgenic mice is likely due to increased affinity of these lipoproteins for the LDL receptor. It was reported that homozygotes and heterozygotes represented 80 and $50 \%$ decreases in plasma apo B levels, respectively, compared with controls (18). Considering that the current kinetic studies were performed by injection of VLDL and LDL prepared from heterozygotes into homozygotes, the 3.0- and 2.4-fold increases in the respective removal rates of VLDL and LDL can account for the decreases in plasma apo B levels and hence the reduction in plasma lipoproteins containing apo $B$ in transgenic mice. From the VLDL apo B levels in VLDL used for the kinetic study, it was estimated that the calculated synthetic rates of VLDL apo B in controls and transgenic mice were 10.6 and $11.8 \mathrm{mg} / \mathrm{kg}$ body wt per d, respectively. The similar production rates of VLDL apo B are consistent with the similar levels of hepatic apo B mRNA (Fig. 8). On the other hand, there were no significant differences in the kinetics of HDL between the two groups. This is consistent with the observation that homozygotes showed only a slight decrease in HDL cholesterol level.

In addition to VLDL and LDL, the retinyl palmitate-loading test demonstrated that overexpression of apo E caused a profound and dose-dependent effect on the metabolism of chylomicron remnants. The retinyl palmitate methodology as a specific marker for chylomicron and chylomicron remnants has been under some criticism in human studies because a considerable portion of plasma retinyl palmitate can be transferred to denser lipoproteins, especially in the late phase of the loading test (34). However, the transfer would be negligible in the present study because mice lack cholesteryl ester transfer protein activity (35). It is theoretically possible that decreased plasma levels of retinyl palmitate in transgenic mice may be due to decreased intestinal absorption of retinyl palmitate. However, this improbable theory can be excluded by the results of plasma free retinol levels. After intestinal absorption, dietary retinoids are incorporated into chylomicrons, taken up by the liver via the portal circulation, and stored in the liver as retinyl esters. Some retinyl esters in the liver are hydrolyzed and retinol is secreted into the circulation in a bound form with retinol-binding protein (for review see reference 36 ). Thus, in a 
physiological state, there is a considerable stable level of retinol in plasma, whereas retinyl palmitate is undetectable by common techniques. Therefore, the peak in the plasma level of retinol after retinyl palmitate loading reflects intestinal absorption and hepatic uptake of dietary retinyl palmitate. The peaks of plasma retinol levels in transgenic lines were comparable to that in controls, suggesting that similar amounts of challenged retinyl palmitate were absorbed in intestines and carried to the livers in each group. Since intestinal expression of apo E is minimal in the transgenic line used in this study (17), nascent chylomicrons produced in the intestines should be devoid of apo E. It has been reported that chylomicrons incubated with apo $E$ are taken up more efficiently by the perfused liver from an estradiol-treated rat $(6,37)$. The present study is the first report that hepatic overexpression of apo $E$ enhances clearance of chylomicron remnants in vivo, although the lower baseline level of plasma triglycerides in transgenic mice in itself might have a minimal effect on the plasma clearance of retinyl palmitate. In their conversion to remnants, chylomicrons are supposed to acquire rat apo $\mathrm{E}$ molecules somewhere in circulation in the transgenic line. Interestingly, microscopic examination after immunohistochemical staining demonstrated high staining for rat apo $E$ from the transgene in the sinusoidal area of the liver in homozygotes (unpublished observation), as observed in rat liver (38). Abundant apo E molecules in these areas may be involved in the hepatic uptake of chylomicron remnants trapped in the space of Disse. The identification of receptor(s) responsible for uptake of chylomicron remnants enriched with apo $\mathrm{E}$ is conflicting. The similar results of the retinyl palmitate-loading test in transgenic mice on a normal diet and a high cholesterol diet, which showed decreased LDL receptor activity, suggest considerable involvement of a putative chylomicron remnant receptor. Supporting this, it was reported that clearance of chylomicron remnants in LDL receptor deficiency is normal in the retinyl palmitate-loading test on the patients with familial hypercholesterolemia (39). Meanwhile, it was reported that the LDL receptor plays a large role in the clearance of chylomicron remnants in rats from study of the effect of injection of anti-LDL receptor antibody (40).

Cholesterol feeding caused a marked increase in lipoproteins containing apo B in normal mice (Fig. 2). The marked increase in liver cholesterol content (Table I) and slight increase in apo B mRNA level (Fig. 8) suggest that the increase in plasma cholesterol is due to increases of both cholesterol content and number of these particles. In rodents, both apo B100 and apo B48 seem to be produced in the liver (41) and it was reported that the apo B48 content was relatively increased rather than the apo B100 content when fed a high cholesterol diet (42). Because apo B48 has no affinity for LDL receptors, cholesterol-rich lipoproteins containing apo B48 would accumulate in the circulation of cholesterol-fed control mice unless an appropriate number of apo E molecules were present on the particles, even if residual LDL receptors were still active. Transgenic mice on a high cholesterol diet also showed high cholesterol contents in the liver, indicating that dietary cholesterol was absorbed and finally carried to the liver as well as in cholesterol-fed controls. Thus, it is likely that transgenic mice also synthesize as much cholesterol-rich lipoproteins as controls. However, additional apo $E$ from the transgene could facilitate clearance of cholesterol-rich lipoprotein particles via residual LDL receptors and counterbalance increased production of cholesterol-rich lipoproteins, resulting in resistance against hypercholesterolemia. In transgenic mice, the total cholesterol influx into the liver would be similar to that in controls receiving either a normal or high cholesterol diet because the low plasma levels and the high efficient uptake of lipoproteins containing apo B would be balanced. This explains why transgenic and control mice have similar amounts of liver cholesterol, as observed in transgenic mice overexpressing LDL receptor (43) and similar LDL receptor activity on either diet in the steady states.

The clearances of these cholesterol-rich lipoproteins in cholesterol-fed mice appears to be via the LDL receptor pathway because the expression of LDL receptor protein was not completely suppressed. However, it is difficult to determine the contribution of the chylomicron remnant receptor exactly, especially in the clearance of lipoproteins containing apo B in cholesterol-fed transgenic mice. LRP (30), a candidate for the apo $\mathrm{E}$ receptor, can take up $\beta$ VLDL enriched with apo $\mathrm{E}$ $(44,45)$. Plasma VLDL particles in cholesterol-fed transgenic mice are likely to be similar to $\beta$ VLDL or cholesterol-rich chylomicron remnants and are likely to be cleared via LRP. On a high cholesterol diet, expression of LRP was not suppressed in both transgenic and control mice (Fig. 7) (44), whereas hepatic LDL receptors were decreased. It is possible that relative contribution of LRP to the clearance of lipoproteins containing B48 may be greater when these lipoproteins are enriched with cholesterol and apo E.

Many of the observations in apo $\mathrm{E}$ transgenic mice, such as marked reduction in lipoproteins containing apo B and resistance against diet-induced hypercholesterolemia, were very similar to those in transgenic mice overexpressing LDL receptor $(43,46)$. This is not surprising since the two transgenic lines represent the augmentation of the same interaction between the ligand and the receptor by overexpression of either. However, there are expected to be also some distinctions between the two lines because another ligand or apo B100, and another receptor or chylomicron remnant receptor, would also be involved in lipoprotein metabolism. To assess the quantitative role of the chylomicron remnant receptor, which may be LRP, further studies are required using a manipulation to totally suppress the LDL receptor in the apo E transgenic line, such as by combination with gene targeting of LDL receptor.

In the current study, it was found that overexpression of apo $E$ has a profound effect on clearance of lipoproteins containing apo B48 and apo B100, and plays a crucial role in regulation of the metabolism of these lipoproteins. Increased plasma apo E levels are frequently observed in hyperlipidemic patients and animals. Increased production of apo $E$ may be a compensatory reaction to clear high plasma levels of lipids, although in humans the plasma apo $E$ level even if increased may be insufficient to decrease plasma lipids in hyperlipidemic patients. The present data also suggest that exogenous administration of apo $E$ may be of therapeutic benefit to patients with hyperlipidemia and atheroma.

\section{Acknowledgments}

We are very grateful to Dr. M. S. Brown and Dr. J. L. Goldstein for a helpful discussion.

This work was supported by a grant for diabetes research from Otsuka Pharmaceutical Co., Ltd. (Tokushima, Japan). 


\section{References}

1. Mahley, R. W. 1988. Apolipoprotein E: cholesterol transport protein with expanding role in cell biology. Science (Wash. DC). 240:622-630.

2. Brown, M. S., and J. L. Goldstein. 1986. A receptor pathway for cholesterol homeostasis. Science (Wash. DC). 232:34-37.

3. Elshourbagy, N. A., W. S. Liao, R. W. Mahley, and J. M. Taylor. 1985 Apolipoprotein E mRNA is abundant in the brain and adrenals, as well as in the liver, and is present in other tissues of rats and marmosets. Proc. Natl. Acad. Sci. USA. 82:203-207.

4. Ignatius, M. J., E. M. Shooter, R. E. Pitas, and R. W. Mahley. 1987 Lipoprotein uptake by neuronal growth cones in vitro. Science (Wash. DC). 236:959-962.

5. Pitas, R. E., T. L. Innerarity, K. S. Arnold, and R. W. Mahley. 1979. Rate and equilibrium constants for binding of apo-E HDLc (a cholesterol-induced lipoprotein ) and low density lipoproteins to human fibroblasts: evidence for multiple receptor binding of apo-E HDLc. Proc. Natl. Acad. Sci. USA. 76:2311-2315.

6. Windler, E., Y. Chao, and R. J. Havel. 1980. Regulation of the hepatic uptake of triglyceride-rich lipoproteins in the rat. J. Biol. Chem. 255:8303-8307.

7. Windler, E. E. T., P. T. Kovanen, Y. Chao, M. S. Brown, R. J. Havel, and J. L. Goldstein. 1980. The estradiol-stimulated lipoprotein receptor of rat liver. A binding site that mediates the uptake of rat lipoproteins containing apoproteins $B$ and E. J. Biol. Chem. 255:10464-10471.

8. Eisenberg, S., G. Friedman, and T. Vogel. 1988. Enhanced metabolism of normolipidemic human plasma very low density lipoprotein in cultured cells by exogenous apolipoprotein-3. Arteriosclerosis. 8:480-487.

9. Ishibashi, S., N. Yamada, H. Shimano, N. Mori, H. Mokuno, T. Gotoda, M. Kawakami, T. Murase, and F. Takaku. 1990. Apolipoprotein E and lipoprotein lipase secreted from human monocyte-derived macrophages modulate very low density lipoprotein uptake. J. Biol. Chem. 265:3040-3047.

10. Mokuno, H., N. Yamada, H. Shimano, S. Ishibashi, N. Mori, K. Takahashi, T. Oka, T. H. Yoon, and F. Takaku. 1991. The enhanced cellular uptake of very-low-density lipoprotein enriched in apolipoprotein E. Biochim. Biophys. Acta. 1082:63-70.

11. Shimano, H., C. Fukazawa, Y. Shibasaki, N. Mori, T. Gotoda, K. Harada, M. Shimada, N. Yamada, Y. Yazaki, and F. Takaku. The effect of apo E secretion on lipoprotein uptake in transfected cells. Biochim. Biophys. Acta. 1086:245254.

12. Yamada, N., D. M. Shames, J. B. Stoudmire, and R. J. Havel. 1986. Metabolism of lipoproteins containing apolipoprotein B-100 in blood plasma of rabbits: heterogeneity related to the presence of apolipoprotein E. Proc. Natl. Acad. Sci. USA. 83:3479-3483.

13. Yamada, N., D. M. Shames, and R. J. Havel. 1987. Effect of low density lipoprotein receptor deficiency on the metabolism of apolipoprotein B-100 in blood plasma. J. Clin. Invest. 80:507-515.

14. Yamada, N., D. M. Shames, K. Takahashi, and R. J. Havel. 1988. Metabolism of apolipoprotein B-100 in large very low density lipoproteins of blood plasma. J. Clin. Invest. 82:2106-2113.

15. Yamada, N., H. Shimano, H. Mokuno, S. Ishibashi, T. Gotohda, M Kawakami, Y. Watanabe, Y. Akanuma, T. Murase, and F. Takaku. 1989. Increased clearance of plasma cholesterol after injection of apolipoprotein $\mathrm{E}$ into Watanabe heritable hyperlipidemic rabbits. Proc. Natl. Acad. Sci. USA. 86:665669.

16. Mahley, R. W., K. H. Weisgraber, M. M. Hussain, B. Greenman, M Fisher, T. Vogel, and M. Gorecki. 1989. Intravenous infusion of apolipoprotein E accelerates clearance of plasma lipoproteins in rabbits. J. Clin. Invest. 83:21252130.

17. Shimano, H., N. Yamada, M. Shimada, N. Ohsawa, C. Fukazawa, Y. Yazaki, F. Takaku, and M. Katsuki. 1991. Hepatic and renal expression of rat apolipoprotein $\mathrm{E}$ under control of the metallothionein promotor in transgenic mice. Biochim. Biophys. Acta. 1090:91-94.

18. Shimano, H., N. Yamada, M. Katsuki, M. Shimada, T. Gotoda, K. Harada, T. Murase, C. Fukazawa, F. Takaku, and Y. Yazaki. 1992. Overexpression of apolipoprotein $\mathrm{E}$ in transgenic mice: a marked reduction in plasma lipoproteins except high density lipoprotein, and resistance against diet-induced hypercholesterolemia. Proc. Natl. Acad. Sci. USA. 89:1750-1754.

19. Allain, C. C., L. S. Poon, C. S. G. Chan, W. Richmond, and P. C. Fu. 1974. Enzymatic determination of total serum cholesterol. Clin. Chem. 20:470-475.

20. Havel, R. J., H. A. Eder, and J. H. Bragdon. 1955. The distribution and chemical composition of ultracentrifugally separated lipoproteins in human serum. J. Clin. Invest. 34:1345-1353.

21. McFarlane, A. S. 1958. Efficient trace-labelling of proteins with iodine. Nature (Lond.). 182:53-54.

22. Yamada, N., and R. J. Havel. 1986. Measurement of apolipoprotein B radioactivity in whole blood plasma by precipitation with isopropanol. J. Lipid Res. 27:910-912.

23. Matthews, C. M. E. 1957. The theory of tracer experiments with ${ }^{131}$ I-labelled plasma proteins. Phys. Med. Biol. 2:36-53.
24. Shimano, H., N. Yamada, S. Ishibashi, K. Harada, A. Matsumoto, N. Mori, T. Inaba, K. Motoyoshi, H. Itakura, and F. Takaku. 1990. Human monocyte colony-stimulating factor enhances the clearance of lipoproteins containing apolipoprotein B-100 via both low density lipoprotein receptor-dependent and -independent pathways in rabbits. J. Biol. Chem. 265:12869-12875.

25. Kovanen, P. T., M. S. Brown, and J. L. Goldstein. 1979. Increased binding of low density lipoprotein to liver membranes from rats treated with 17alpha-ethinyl estradiol. J. Biol. Chem. 254:11367-11373.

26. Laemmli, U. K. 1970. Cleavage of structural proteins during the assembly of the head of bacteriophage T4. Nature (Lond.). 227:680-685.

27. Shimano, H., H. Aburatani, N. Mori, S. Ishibashi, T. Gotoda, H. Mokuno, M. Kawakami, Y. Akanuma, F. Takaku, T. Murase, et al. 1988. Down-regulation of hepatic LDL receptor protein and messenger RNA in fasted rabbits. $J$. Biochem. 104:712-716.

28. Chomczynski, P., and N. Sacchi. 1987. Single-step method of RNA isolation by acid guanidinium thiocyanate-phenol-chloroform extraction. Anal. Biochem. 162:156-159.

29. Matsumoto, A., H. Aburatani, Y. Shibasaki, T. Kodama, F. Takaku, and H. Itakura. 1987. Cloning and regulation of rat apolipoprotein B mRNA. Bio chem. Biophys. Res. Commun. 142:92-99.

30. Hertz, J., U. Hamann, S. Rogne, O. Myklebost, H. Gausepohl, and K. K. Stanley. 1988. Surface location and high affinity for calcium of a 500-kd liver membrane protein closely related to the LDL-receptor suggest a physiologica role as lipoprotein receptor. EMBO (Eur. Mol. Biol. Organ.) J. 7:4119-4127.

31. Feinberg, A. P., and B. Vogelstein. 1984. Addendum A technique for radiolabeling DNA restriction endonuclease fragments to high specific activity. Anal. Biochem. 137:266-267.

32. Mclean, J. W., C. Fukazawa, and J. M. Taylor. 1983. Rat apolipoprotein E mRNA. cloning and sequencing of double-stranded cDNA. J. Biol. Chem. 258:8993-9000.

33. Rajavashisth, T. B., J. S. Kaptein, K. L. Reue, and A. J. Lusis. 1985. Evolution of apolipoprotein E: mouse sequence and evidence for an 11-nucleotide ancestral unit. Proc. Natl. Acad. Sci. USA. 82:8085-8089.

34. Krasinski, S. D., J. S. Cohn, R. M. Russel, and E. J. Schaefer. 1990. Postprandial plasma Vitamin A metabolism in humans: a reassessment of the use of plasma retinyl esters as markers for intestinally derived chylomicrons and their remnants. Metabolism. 39:357-365.

35. Agellon, L. B., A. Walsh, T. Hayek, P. Moulin, X. C. Jiang, S. A. Shelanski, J. L. Breslow, and A. R. Tall. 1991. Reduced high density lipoprotein cholesterol in human cholesteryl ester transfer protein transgenic mice. J. Biol. Chem. 266:10796-10801.

36. Blomhoff, R., M. H. Green, T. Berg, and K. R. Norum. 1990. Transport and storage of vitamin A. Science (Wash. DC). 250:399-404.

37. Windler, E., and R. J. Havel. 1985. Inhibitory effects of $C$ apolipoproteins from rats and humans on the uptake of triglyceride-rich lipoproteins and their remnants by the perfused rat liver. J. Lipid Res. 26:556-565.

38. Hamilton, R. L., J. S. Wong, L. S. S. Guo, S. Krisans, and R. J. Havel. 1990. Apolipoprotein E localization in rat hepatocytes by immunogold labeling of cryothin sections. J. Lipid Res. 31:1589-1603.

39. Rubinsztein, D. C., J. C. Cohen, G. M. Berger, D. R. van der Westhuyzen, G. A. Coetzee, and W. Gevers. 1990. Chylomicron remnant clearance from the plasma is normal in familial hypercholesterolemic homozygotes with defined receptor defects. J. Clin. Invest. 86:1306-1312.

40. Choi, S. Y., L. G. Fong, M. J. Kirven, and A. D. Cooper. 1991. Use of an anti-low density lipoprotein receptor antibody to quantify the role of the LDL receptor in the removal of chylomicron remnants in the mouse in vivo. J. Clin. Invest. 88:1173-1181.

41. Tennyson, G. E., C. A. Sabatos, K. Higuchi, N. Meglin, and H. B. Brewer, Jr. 1989. Expression of apolipoprotein B mRNAs encoding higher- and lowermolecular weight isoproteins in rat liver and intestine. Proc. Natl. Acad. Sci. USA. 86:500-504.

42. Lusis, A. J., B. A. Taylor, D. Quon, S. Zollman, and R. C. LeBoeuf. 1987. Genetic factors controlling structure and expression of apolipoprotein $B$ and $E$ in mice. J. Biol. Chem. 262:7594-7604.

43. Yokode, M., R. E. Hammer, S. Ishibashi, M. S. Brown, and J. L. Goldstein. 1990. Diet-induced hypercholesterolemia in mice: prevention by overexpression of LDL receptors. Science (Wash. DC). 250:1273-1275.

44. Kowal, R. C., J. Herz, J. L. Goldstein, V. Esser, and M. S. Brown. 1989. Low density lipoprotein receptor-related protein mediates uptake of cholesteryl esters derived from apoprotein E-enriched lipoproteins. Proc. Natl. Acad. Sci. USA. 86:5810-5814.

45. Lund, H., K. Takahashi, R. L. Hamilton, and R. J. Havel. 1989. Lipoprotein binding and endosomal processing of the low density lipoprotein receptor-related protein (LRP) in rat liver. Proc. Natl. Acad. Sci. USA. 86:9318-9322.

46. Hofmann, S. L., D. W. Russell, M. S. Brown, J. L. Goldstein, and R. E. Hammer. 1988. Overexpression of low density lipoprotein (LDL) receptor eliminates LDL from plasma in transgenic mice. Science (Wash. DC). 239:12771281. 